\title{
Global Health Governance and Pandemics: Uncertainty and Institutional Decision-Making
}

Sudeepa Abeysinghe

Abstract Because novel strains of influenza can spread quickly across the globe, they require swift decision-making, often in the absence of complete or unambiguous evidence. Such disease also necessitates the coordination of multiple actors, whose interests are not always aligned. Pandemic events therefore place pressure on the cohesion and efficacy of the complex architecture of global health governance. This chapter assesses the global health management of the 2009 pandemic, focusing especially on the actions and criticisms of the World Health Organization (WHO), and assessing the strengths and limitations of the WHO's pandemic management process. The chapter highlights the difficulties involved in reacting to an evolving and uncertain risk, and situates the problem of uncertainty within the context of shifts in the WHO's institutional role within global health governance.

\footnotetext{
S. Abeysinghe $(\square)$

University of Edinburgh, Edinburgh, UK e-mail: sudeepa.abeysinghe@ed.ac.uk
}

(C) The Author(s) 2019

K. Bjørkdahl and B. Carlsen (eds.), Pandemics, Publics, and Politics, https://doi.org/10.1007/978-981-13-2802-2_2 
Keywords COVID-19 • HINI 2009 pandemic • Risk • Uncertainty • Institutions · Governance · WHO $\cdot$ Contestation

Severe epidemic and pandemic threats are potentially catastrophic. With increasing globalization, risk management needs to be undertaken at the global level. Understanding risk management as a problem of global health governance is therefore key to appreciating contemporary action surrounding infectious disease. Managing crises through the structures of global health can be challenging in several ways. Emerging and reemerging diseases are often novel (e.g. new strains of virus or bacteria) and/or poorly understood. Even during events where many of the scientific aspects of the disease are well-known (e.g. the West Africa Ebola outbreak of 2014), institutional, social, cultural and political contexts differ. Further, when considering globalised threats, multiple actors and interests must be represented and weighed against each other. These complexities are evident when focusing on the case of the WHO's management of $\mathrm{A}(\mathrm{HINl}) \mathrm{pdm} 09$ - i.e. the 2009 pandemic.

The WHO provides information and coordinates global reactions to influenza pandemics. In the past, the WHO had been more directive in its authority of epidemic disease, for example, in the malaria or tuberculosis control campaigns (Beigbeder 1998; Fee et al. 2008). Under the International Health Regulations (IHR) (2005) the WHO is pivotal in the initial definition of pandemic events, effectively serving to categorise a threat as a pandemic. This act of definition is bound by classificatory mechanisms (through application of the 2009 Pandemic Alert Phases) which trigger a public health response. Though most epidemic events can be easily distinguished, in some cases the construction of the event is fragile and unstable, lending to contestation. In such cases, the assumptions behind the phenomenon unravel. Prior to $\mathrm{HlNl}$, it was generally assumed by key scientific and institutional stakeholders (including the WHO itself) that a pandemic event could be easily identified (Doshi 2011). This chapter will show that, up until HINl the status of a pandemic event was taken for granted. What HINI and the WHO's response did was to expose the fragility of the pandemic as a scientific fact. Following this, not only was the management of the threat called into question, but also the WHO's authority (Abeysinghe 2017).

The following analysis is drawn from broader work which used qualitative document analysis of texts produced by the WHO and the Council 
of Europe to examine the construction and subsequent contestation of the 2009 pandemic. This included all publicly available H1Nl-related WHO documents such as situation updates, Director-General Speeches and Statements, Pandemic briefing notes, press briefings and key policy documents. Council of Europe documents included the tabled motion "Faked Pandemics: A Threat to Public Health" (2009), transcripts and documents related to several key committees and parliamentary sittings to debate the issue, and the final report "The Handling of the HINl Pandemic: More Transparency Needed" (2010). These texts were assessed through thematic coding and discourse analysis (see also Abeysinghe 2016). The chapter captures a particular point in time in respect to the WHO's actions. Indeed, the experience of $\mathrm{HINl}$ resulted in shifts in many of the organisation's pandemic management processes (most notably in terms of the inclusion of measures of severity in official definitions) (Fineberg 2014). However, assessing the debate around the WHO's management of HINl both sheds light on those events but also illuminates the wider nature of the institutional governance of disease risk. In this chapter, I will argue that the instability of the fact of the pandemic was a result of the embedded uncertainty surrounding $\mathrm{HINl}$, the lack of pre-existing clarity surrounding the concept of pandemic, and the positioning of the WHO within global public health.

\section{Governing Global Health Risk}

In addition to issues of global health governance, I will argue that this case study reflects aspects of the transition between normal science and a post-normal form of managing risk. A key problem of $\mathrm{HINl}$ is the problem of the construction and management of risk. Normal science surrounding risk, following Kuhn (1970), is conducted by disciplinary-bound scientists, producing knowledge about a problem of their own construction. This knowledge is transformed into a stable and consistent set of facts, having undergone scientific closure (Latour and Woolgar 1979). According to this theory, where institutions can rely upon a stable understanding of risk and can impose taken-for-granted management strategies (such as, with influenza, the use of mass vaccination), they are effectively acting within this mode of risk knowledge. While normal science is also incomplete, the problems of this mode of science can generally be (thought) solvable by scientific advances, and the knowledge surrounding these risks is often relatively stable. 
In contrast, forms of knowledge that are strongly contextualised where "discovery, application and use are closely integrated" (Gibbons et al. 1994: 46), result in a different orientation to risk. Under these conditions, the evidence produced is itself uncertain and often contradictory. This is because, as in the case of $\mathrm{HINl}$, the epidemiological evidence (and, to a lesser extent, virological evidence) unfolds at a timescale that is slower than that of policymaking needs. This post-normal form of science is particularly relevant when assessing policy production surrounding risks, where "the facts are inevitably uncertain, the values in dispute" (Ravetz 2004: 351) and the responsible institution must be concerned with "the management of a reality that has irreducible complexities and uncertainties" (Funtowicz and Ravetz 1994: 1882). All pandemic strains are previously unexperienced strains of influenza. The limited knowledge around novel disease is combined with the future orientation of the risk. This means that early decisions must be made to prevent a more severe crisis. In addition, the emerging knowledge base produces diverse explanations of the problem and thereby a diverse choice of policy reactions.

This wider problem of definitional uncertainty is coupled with the complexity of the governance of globalised infectious disease. As seen in the case of $\mathrm{HINl}$, divisions of authority between global and state actors (i.e. WHO and national governments) are often ambiguous (Miller 2004), leading to misunderstandings around roles and jurisdiction (Szlezak et al. 2010). The IHR does separate the roles of the WHO (coordination and provision of information) and national governments (reporting to the WHO and managing disease control at the national level). However, the erosion of the jurisdiction of the nation state, and the rise of health problems which transgress national boundaries, leaves authority over globalised public health risk indefinite (Szlezak et al. 2010; Taylor 2005). As opposed to older international models of public health, within global health governance the WHO now presents itself as primarily concerned with the coordination and facilitation of dialogue among various global public policy networks, which include not only state actors but also corporations, NGOs and other elements of civil society. Thus, although some have suggested that increasing interdependence strengthens the role of organisations such as the WHO (particularly due to their perceived neutrality) (Taylor 2005; Walt 1988), there has arguably been an overall weakening of authority, whereby the WHO has been relegated to a facilitator rather than a leader. Diverse actors within 
global health, including in this case pharmaceutical corporations, are treated as partners (Buse and Walt 2000; Ollila 2005). This also acted as a source of tension surrounding the WHO's actions around $\mathrm{HINl}$.

\section{HiNl and the World Health Organization}

The designation of a pandemic threat relies on a number of seemingly well-defined and unproblematic characteristics. Prior to the HINl case, these aspects were taken by the WHO to be objectively observable and/ or quantifiable. However, these components of definition can all to some extent be made fragile and tenuous. As the HINl pandemic (and the controversy surrounding it) developed, the concept of pandemic itself was re-problematised and the terms of definition became destabilised. A key early point in the construction of this event was the act of defining the spread of $\mathrm{HINl}$ as a pandemic.

Prior to the controversy around the handling of $\mathrm{HlNl}$, the concept of pandemic was treated by the WHO (and other key actors) as relatively unproblematic (Abeysinghe 2013; Doshi 2011). In defining $\mathrm{HINl}$ as a pandemic case the WHO narrative necessarily linked the virus with the broader concept of pandemic. In the early stages of the event, the WHO assumed that any pandemic (including $\mathrm{HINl}$ ) would result in severe health consequences. Key aspects of pandemic disease were emphasised in making this case. These were: the novelty of the viral agent, the unpredictability of the virus, the ability for the virus to spread geographically, the ability for the virus to mutate into different forms, the mass susceptibility of global populations to the virus, and lastly, a differentiation between "pandemic" and seasonal influenza (Abeysinghe 2013).

Of these, it seems the issue of geographical spread was key to both the narrative accounts given by the WHO representatives and the underpinning classificatory documentation of the Pandemic Alert Phases. For example, it was asserted by the WHO that a broad (global) geographical spread is a characterising feature of a pandemic. Thus, for example, Keiji Fukuda (Special Advisor to the WHO Director-General on Pandemic Influenza) focused on issues of novelty and spread in suggesting that:

An easy way to think about pandemic - and actually a way I have sometimes described in the past - is to say: a pandemic is a global outbreak. Then you might ask yourself "What is a global outbreak?" Global outbreak means that we see both spread of the agent - and in this case we see this 
new $\mathrm{A}(\mathrm{HlNl})$ virus to most parts of the world - and then we see disease activities in addition to the spread of the virus. (Fukuda 2009, 26 May)

The ability to spread quickly was therefore assumed to be a notable characteristic of pandemic influenza, and disease activities are presumed to be a function of spread. Thus it was suggested that "[i]nfluenza pandemics must be taken seriously precisely because of their capacity to spread rapidly to every country in the world" (Chan [WHO Director-General] 2009, 29 April). The global spread of a pandemic strain served as evidence warranting concern over the threat.

These notions of spread and novelty are linked with constructions of risk around assertions of the unpredictable nature of the virus. The then WHO Director-General, Margaret Chan asserted that:

Influenza viruses are the ultimate moving target. Their behaviour is notoriously unpredictable. The behaviour of pandemics is as unpredictable as the viruses that cause them. No one can say how the present situation will evolve. (Chan 2009a, 11 June)

This emphasis on unpredictability also highlights the uncertainty experienced by the WHO itself, where the future form of the disease was unknowable yet still needed to be predictively managed. The novelty of the virus also distinguishes the pandemic case from seasonal influenza, where:

...the reason we are paying so much attention to this virus though, is that seasonal influenza viruses have been around the world and have been circulating for many years. And so we understand their behaviour and we know that most people... have some immunity to them; that is what makes them seasonal influenza viruses. But we also know that when a new influenza virus enters the human population, and people do not have immunity to this virus, then the levels of serious illness and the levels of deaths can be higher... (Fukuda 2009, 5 May)

Here, novelty and unpredictability are distinguishing characteristics of pandemic strains, helping to contrast pandemic influenza from seasonal flu.

However, the WHO's explanation of the difference between $\mathrm{HINl}$ and seasonal influenza-which went at the heart of the characterisation of HINl as a pandemic-was often unconvincing (Abeysinghe 2013). 
Even during the early months, the discussions of symptomology and differences between $\mathrm{HINl}$ and seasonal flu were unclear:

In terms of the illness itself, in the people who are developing generally milder illness, this is similar to the kinds of influenza-like illnesses that we see, so this is typically people developing fever, cough, body aches, headaches, and this is generally in keeping with what the milder spectrum of illness is. (Fukuda 2009, 5 May)

Over time, it became increasingly evident that the HINl pandemic would not result in large-scale excess morbidity and mortality. The distinctions between $\mathrm{HINl}$ and seasonal flu became blurred. This was particularly problematic given the widespread (although arguably inaccurate) public perception of "the flu" as a routine and often mild event (Helman 1978; McCombie 1999). That failure to distinguish between seasonal and pandemic influenza-and therefore justify the public health focus on $\mathrm{HINl}$ - is symptomatic of a more fundamental weakness in the construction and communication of $\mathrm{HlNl}$. This was the neglect of the dimension of severity.

In addition to the controversy surrounding the use of vaccines, competing assertions of severity versus mildness were a primary site of contestation amongst global actors, as evidenced within press conferences and meetings. Throughout the course of the pandemic, the WHO moved from a naïve and unproblematic use of the term severity towards a series of redefinitions than increasingly complexified the term. In the early texts it was evident that the WHO placed an emphasis on the importance of determining severity:

The other question that has come to WHO is: "Is severity important?" Of course severity is important. The whole reason why we take action against diseases is because they harm people. If diseases are relatively mild, like colds, then we take certain kinds of precautions, if diseases are very severe, such as avian influenza or HIV, then we take another level of precautions. Clearly severity is an important concept for public health and how we deal with these issues. (Fukuda 2009, 26 May)

Here, severity was suggested to be a fundamental characteristic which defined the risk posed to a population by a pandemic. In the early usage, it was clear that the interest in $\mathrm{HINl}$ as a threat stemmed from its 
probable ability to produce severe disease-the potential severity characterised $\mathrm{HINl}$ as a risk.

However, the pandemic failed to manifest as severe in terms of global morbidity and mortality, this characterisation became increasingly untenable. The linking of severity and risk was increasingly disassociated. This occurred through a redefinition both of the term severity and of the (previously) implied correlation between severity and risk. Though many features of $\mathrm{HlNl}$ mirrored seasonal flu, those which distinguished the pandemic state were highlighted here:

...we understand that this disease is mild in the majority of cases, however, we will have some serious cases, mostly in people with underlying conditions, which is close to the pattern we see in seasonal influenza, but we can expect also some cases in people, previously healthy, who will suffer from this virus directly. (Briand [WHO Global Influenza Programme Director] 2009, 8 May)

In addition, there were renegotiations of the meaning of severity, here in suggesting that severity (rather than a stable aspect of the disease) can be mutable over time and place:

...we have good reason to believe that this pandemic, at least in its early days, will be of moderate severity. As we know from experience, severity can vary, depending on many factors, from one country to another. (Chan 2009, 17 June)

And finally, movements towards minimising the focus on severity:

When you think about severity, you have at least three problems....The first is defining what you mean by severity. So, are you talking about mortality? Are you talking about morbidity, or illness? Are you talking about some combination of the numbers and the severity in meaning 'severity'? What do you really mean by it?...

Second challenge is, how do you measure it? Not simply in theory - but how do you measure it practically and in real time, in a way that can be used to inform your decisions?

And third, how do you account for the variety in severity in different settings at the same time? So you may have a country experiencing a degree of severity very different to another...or within a country, you may have 
sub-populations experiencing degrees in severity very different to the other [populations]. (Fineberg [Chair of the International Health Regulations Committee] 2010, 14 April)

It is clear therefore that the WHO faced great difficulty in mobilising an effective discourse of severity, and therefore, risk. As a result, by the final stages of the pandemic, attempts were actually made by the WHO to abandon the concept of severity altogether, by suggesting that severity is an ambiguous and meaningless term. However, given that social experiences and understandings of the term pandemic' assume that a pandemic disease will be a severe disease (Barry 2004; Herzlich and Pierret 1987; Wald 2008), this added to the instability of the institutional construction and representation of the event.

This problem was magnified by the institutional process through which the WHO handles the definition of global infectious disease events. The Pandemic Alert Phases (outlining the stages in declaring and handling a pandemic) found in the WHO's core document regarding influenza management, the Pandemic Influenza Preparedness and Response (2009) guidance document, had been updated just prior to the first recorded incidence of $\mathrm{HINl}$. In approaching $\mathrm{HINl}$, member states were confused and reacted with criticism to the WHO's conceptualisation of the Pandemic Phases. From the early stages of the HINl threat, there was an intense level of scrutiny surrounding the Phases, both in terms of the WHO's categories and in the context of the Organisation's timing of Phase increases. In addition to the consternation surrounding the 2009 redefinitions, the practical implications of the Phases produced misunderstanding; the WHO and its wider audience (particularly member states) adopted differing interpretations of the implications of the Phase categories.

During the early stages of the threat, the WHO was criticised for not acting quickly enough in moving $\mathrm{HINl}$ through the Phases. The failure of the Phases as a classificatory scheme is reinforced through an exchange where a journalist (David Brown, Washington Post) questions why the pandemic has not been declared since, by the WHO's own definitions, the situation appears to warrant it. In this exchange, Brown asks:

...if you could please address the question of why there seems to be so much reluctance on going to Phase 6? It is a very clear definition. The point was made, you know, long ago, that it does not measure severity. 
What is to be lost by saying that it is community spreading, in the community and more than one place - which it obviously is - more than one region, we are going to go to Phase 6 and it is a mild Phase 6 . Why not just bite the bullet? (Fukuda 2009, 26 May)

In response, Keiji Fukuda (WHO Special Advisor on Pandemic Influenza and Assistant Director-General) asserted that:

The answer to that is really almost another question which is: "what is to be gained by going to another Phase?"....Right now, when we look at the request: "Why cannot WHO look at going to Phase 6" coming from the countries.... And so, behind that question is the sense that many countries are already doing things that are necessary right now to address the situation. But if you go and declare Phase 6 without very clear evidence that there is a sort of change in the global situation, it can lead to extra work for countries without much gain, it can lead to some level of panic, it can lead to some level of cynicism that something is being declared but which is not usefully producing something in terms of public health benefit and gain. (Fukuda 2009, 26 May)

This quote indicates that, even at the pre-declaration stage of the event, the WHO attempted to minimise potential criticisms of prematurely/ unnecessarily calling a pandemic. This was despite that fact that WHO guidelines themselves suggested that the widespread and novelty of $\mathrm{HINl}$ defined it as a pandemic strain almost immediately following discovery (Cohen and Enserink 2009). The WHO was put in this position due to the incongruity of the Phase classifications in relation to the social understanding of pandemic.

At the other end of the event, the WHO was criticised for overextending the pandemic period and in some cases for having called the spread of HINl a pandemic at all (a question that will be addressed in the section below). The Phases revolve around the issue of geographical spread:

At the WHA [World Health Assembly 2009], what the countries raised was a concern and they said that currently the criteria from going to 5 and 6 are based on geographical spread, and this is true. (Fukuda 2009, 22 May)

However, the spread of disease (including mildly symptomatic or asymptomatic infection) is not necessarily directly correlated with high risk. 
As the discussion regarding the Phases and severity unfolded, differences in the perception and definition of these terms became increasingly clear:

...what the countries said is that we are in the mixed situation and we are concerned that if we go into Phase 6 the message to our populations will be: "You should be very afraid", whereas in fact we [the WHO] think that it indicated that the virus is spreading out but the level of fear should not go up and there should not be an increase in anxiety. (Fukuda 2009, 22 May)

Subsequent to the experience of $\mathrm{HINl}$, the problem of severity is now more closely incorporated into WHO standards for defining a pandemic event. However, in terms of $\mathrm{HINl}$, this neglect of severity in the formal mechanisms for managing the disease was a fundamental weakness of the construction of the problem of $\mathrm{HlNl}$.

\section{Implications of the WHO's CONSTRUCTION OF HINl}

After a risk is constructed, a solution must be presented. A critical part of the WHO's institutional management of the HINl pandemic risk was their recommendation of preventative strategies. The Organisation emphasised the importance of vaccinations. By referring to their historical utility and efficacy, vaccines were represented by the WHO as fundamental to prevention. Contemporary responses to risk often result in a (sometimes arbitrary) choice from amongst a plurality of management strategies. HlNl occurred not only under conditions of technical and scientific uncertainty, but also under specific institutional circumstances. Policymakers tend to simplify and perceive problems in ways that limit the perceived scope of potential solutions (Janes and Corbett 2009). Given the inherent scientific uncertainty embedded within the problem of $\mathrm{HINl}$, institutional history with mass vaccination may have helped to determine the course of action.

Historically, the WHO has turned to mass immunisation campaigns as a reaction to global public health disasters. It is therefore unsurprising that immunisation was forwarded as an effective strategy against $\mathrm{HINl}$, despite (or in fact given) the under-evidenced nature of the problem. It was suggested that "all countries will need access to vaccines" (Fukuda 2009, 24 September) to effectively deal with HINl. From the initial discovery of the viral spread, vaccinations were focused upon as a valuable reaction. As the WHO put it: 
Why are we so interested in vaccines against this new virus? It is because we all know that vaccines are an extremely effective public health tool and in addition, vaccines against seasonal influenza are protective against the disease - in severe disease - of millions of people every year. So, therefore, it is generally recognized and accepted that it would be critically important to have a vaccine if you want to stop the pandemic that might be coming with this virus. (Fukuda 2009, 1 May)

Vaccinations were therefore strongly advocated as the most effective method of minimising the risk of HINl in the WHO's perspective on the pandemic. The efficacy and safety of vaccines was highlighted and key work was performed in coordinating the production and supply of vaccines.

This emphasis on mass vaccination was a key site of contestation of the actions of the WHO. The Council of Europe's interest in the WHO's handling of HINl began at the end of 2009. One of the loudest voices of criticism of the actions of the WHO came from the German epidemiologist and Council of Europe parliamentarian Wolfgang Wodarg. This was the first institutional critic of the WHO's handling of HINl. Wodarg presented a recommendation, endorsed by thirteen other members, to the Council on the 18th of December 2009 entitled "Faked Pandemics: A Threat to Public Health". The motion suggested that:

In order to promote their patented drugs and vaccines against flu, pharmaceutical companies have influenced scientists and official agencies, responsible for public health standards, to alarm governments worldwide. They have made them squander tight health care resources for inefficient vaccine strategies and needlessly exposed millions of people's health to the risk of unknown side-effects of insufficiently tested vaccines....

The definition of an alarming pandemic must not be under the influence of drug-sellers. The member states of the Council of Europe should ask for immediate investigations in the consequences at national as well as European levels. (Wodarg 2009, 18 December)

This motion foreshadowed what would become key themes in the debate surrounding the actions of the WHO, namely assertions of the undue alarm caused by the declaration of a pandemic and the inappropriate influence of the vaccine manufacturing industry upon the WHO's 
actions. This was all associated with the primary claim that a "true" pandemic state had not existed.

The WHO did not present either itself or its actions in a convincing manner, leaving the facts of the pandemic liable to contestation. Given that one of the WHO's primary roles in global epidemic management is in the communication of information, the failure to produce a robust narrative around $\mathrm{HINl}$ was key to the subsequent contestation. For the Council of Europe, the WHO's actions appeared not to have been supported by scientific/objective evidence. The allegedly "unscientific" actions of the WHO were presented as a key issue. For example, the Council of Europe rapporteur on the issue stated that:

Exactly a year ago, a very bad decision was taken by the World Health Organization that now seems unscientific and irrational. The result of that decision was that the whole world became scared that a major plague was on the way - a new pandemic that would have been as bad, according to reports, as the flu pandemic of 1918. There seems to have been no scientific basis for that decision. (Flynn in Council of Europe Parliamentary Assembly 2010, 24 June)

This quote suggests that the Organisation defied scientific evidence in its decision-making process. However, the climate of scientific uncertainty under which the WHO operated rendered them susceptible to such critique after the events. The Council of Europe fundamentally contested definitions of pandemic, the legitimacy of the WHO's risk narrative surrounding HINl, the WHO's definition of Pandemic Phase categories, and the management strategy emphasising vaccine use. In so doing, through illustrating the ineffectual construction of the $\mathrm{HINl}$ pandemic, the legitimacy and institutional processes of the WHO itself were made susceptible to critique.

More broadly, apart from direct criticisms such as those outlined above, the instability of the WHO's positioning was evident. The WHO was seen by some actors (such as in the Council of Europe's account) as a central directing body. Thus, for example, although the thenDirector-General Margaret Chan appeared to take responsibility when she suggested that "[ $\mathrm{t}]$ he decision to declare an influenza pandemic will fall on my shoulders [and] I can assure you, I will take this decision with utmost care and responsibility" (Chan 2009, 8 May). However, there is also a distinct sense in which the position of the WHO was dependent 
upon the actions of member states and other stakeholders such as pharmaceutical corporations. In this way, input of multiple partners was emphasised. For example, in announcing the decision to declare a pandemic, Chan suggested that Organisation had "conferred with leading influenza experts, virologists, and public health officials" (Chan 2009b, 11 June). This impression of the WHO's actions as being dependent upon and a result of the input of multiple individuals, governments and organisations was clearly distinct from the narratives of critics and commentators more generally, who tended to portray the WHO as solely responsible for making the decision to call a pandemic and dictating reaction (Wodarg 2009; Flynn 2010).

The WHO represented itself as a coordinating body which provided a source of global information. In regards to their narrative and practice of global public health, the practical implications of the blurring of the roles of various stakeholders were evident. A good illustration of these implications was the Organisation's reaction to pharmaceutical manufacturers

...maintaining and engaging the private manufacturing sector has been a very critical step, again, because this group has the unique and essential role in the vaccine manufacturing process....In the first place it's the private sector which makes vaccines .......Also, this group that has really a unique expertise and knowledge of vaccines because of their manufacturing of the vaccines, it's essential for public health really to act on this kind of knowledge and know-how.... (Fukuda 2009, 3 December)

The emphasis on solidarity and treating all actors as partners had important flow-on consequences. For example, throughout it was clear that the WHO emphasised "the absolute need to extend preparedness and mitigation measures to the developing world" (Chan 2009a, 11 June) and engaged in advocacy with pharmaceutical manufactures around the distribution of products. Yet, simultaneously, when faced with actions from member states that went against WHO recommendations (e.g. mass culling of pigs in Egypt, disrupting the freedom of travel of Mexican citizens) little concrete action could be taken. Thus, while the WHO was liable to the initial construction of the pandemic, and held as responsible by various critics, the organisation's role within global health governance limited the ability of the WHO to direct the results of this risk construction. 


\section{Conclusion}

The WHO did not effectively mobilise a stable construction of the HINl pandemic as a public health risk. This ultimately resulted in the contestation of the WHO's actions by other global health actors. In understanding this case study, we can see that the role played by scientific and institutional uncertainty in the politics surrounding the WHO and $\mathrm{HINl}$ is critical. In the context of a novel disease, where science is still in development, the WHO needed to make policy decisions in the absence of concrete evidence. The problem of dealing with an uncertain evidence base meant that the WHO's stance towards the disease over time. As this chapter has shown, this issue was particularly evident in conversations around severity and risk. While this is an understandable tactic in the face of a shifting evidence base, it also meant that the social construction of $\mathrm{HINI}$ as a public health problem was fragile. This opened the WHO's action up to critique, as evidenced by the criticisms of actors within the Council of Europe. This was all set in a context where the WHO's institutional role within the structures of global health governance has been evolving, and where the organisation now must coordinate the interest of diverse global health stakeholders rather than directly manage infectious disease crises.

Uncertainty abounds within the global governance of many politically charged risks. Contemporary "wicked problems" such as climate change, population growth and aging, and food and water scarcity, present important similarities to the prospect of a pandemic. All are global risks of a potentially catastrophic magnitude, and all are similarly framed by contestation and an emerging evidence base. Like the WHO in respect to $\mathrm{HlNl}$, global institutions and national governments are placed in a position where they are forced to act, even while scientific evidence is scarce or conflicting. Representation and social construction are fundamental to the way in which such risks are perceived and managed. As Latour (2004) put it, such risks are not "matters of fact" to be taken for granted, even though they are global "matters of concern" which must be confronted. During $\mathrm{HINl}$, the facts of the case were emerging, but the WHO needed to react to the concern within the context of this underlying uncertainty. These criticisms could perhaps not have been easily anticipated beforehand. However, a more critical reflection on the mismatches between institutional assumptions (e.g. about the 
geographical definitions of the pandemic label) and other constructions of the problem (e.g. a public interest in severity), combined with a more persuasive narrative of risk, may have strengthened the position on the $\mathrm{WHO}$ in managing the pandemic.

\section{REFERENCES}

Abeysinghe, Sudeepa. 2013. When the Spread of Disease Becomes a Global Event: The Classification of Pandemics. Social Studies of Science 43 (6): 905-926.

Abeysinghe, Sudeepa. 2016. Pandemics, Science and Policy: HINI and the World Health Organization. London: Palgrave Macmillan.

Abeysinghe, Sudeepa. 2017. Contesting a Pandemic: The WHO and the Council of Europe. Science as Culture 26 (2): 161-184.

Barry, John. 2004. The Great Influenza: The Epic Story of the Deadliest Plague in History. London: Penguin.

Beigbeder, Yves. 1998. The World Health Organization. The Hague: Martinus Nijhoff. Buse, Kent, and Gill Walt. 2000. Global Private-Public Partnerships, Part II: What Are the Health Issues for global Governance. Bulletin of the World Health Organisation 78 (5): 699.

Cohen, Jon, and Martin Enserink. 2009. After Delays, WHO Agrees: The 2009 H1Nl Pandemic Has Begun. Science 324 (5934): 1496-1497.

Doshi, Peter. 2011. The Elusive Definition of Pandemic Influenza. Bulletin of the World Health Organization 89 (7): 532-538.

Fee, Elizabeth, Marcos Cueto, and Theodore Brown. 2008. WHO at 60: Snapshots from Its First Six Decades. American Journal of Public Health 98 (4): 630-633.

Fineberg, H.V. 2014. Pandemic Preparedness and Response-Lessons from the HINl Influenza of 2009. New England Journal of Medicine 370 (14): $1335-1342$.

Funtowicz, Silvio, and Jerome Ravetz. 1994. Uncertainty, Complexity and PostNormal Science. Environmental Toxicology and Chemistry 13 (12): 1881-1885.

Gibbons, Michael, Camille Limoges, Helga Nowotny, Simon Schwartzman, Peter Scott, and Martin Trow. 1994. The New Production of Knowledge: The Dynamics of Science and Research in Contemporary Societies. London: Sage.

Helman, Cecil. 1978. "Feed a Cold, Starve a Fever": Folk Models of Infection in an English Suburban Community, and Their Relation to Medical Treatment. Culture, Medicine and Psychiatry 2 (2): 107-137.

Herzlich, Claudine, and Janine Pierret. 1987. Illness and Self in Society. Baltimore: John Hopkins University Press.

Janes, Craig, and Kitty Corbett. 2009. Anthropology and Global Health. Annual Review of Anthropology 38: 167-183. 
Kuhn, Thomas. 1970. The Structure of Scientific Revolutions. Chicago: The University of Chicago Press.

Latour, Bruno. 2004. Why Has Critique Run Out of Steam?: From Matters of Fact to Matters of Concern. Critical Inquiry 30: 225-248.

Latour, Bruno, and Steve Woolgar. 1979. Laboratory Life. Beverly Hills: Sage.

McCombie, Susan. 1999. Folk Flu and Viral Syndrome: An Anthropological Perspective. In Anthropology in Public Health: Bridging Differences in Culture and Society, ed. Robert Hahn, 27-43. New York: Oxford University Press.

Miller, Clark A. 2004. Climate Science and the Making of a Global Public Order. In States of Knowledge: The Co-Production of Science and Social Order, ed. S. Jasanoff, 46-66. London: Routledge.

Ollila, Eeva. 2005. Global Health Priorities: Priorities of the Wealthy? Globalization and Health 1 (6): 6-11.

Ravetz, Jerome. 2004. The Post-Normal Science of Precaution. Futures 36 (3): $347-357$.

Szlezak, Nicole, Barry Bloom, Dean Jamison, Gerald Keusch, Catherine Michaud, Suerie Moon, and William Clark. 2010. The Global Health System: Actors, Norms and Expectations in Transition. PLoS Medicine 7 (1): 1-4.

Taylor, Allyn. 2005. Governing the Globalization of Public Health. Journal of Law, Medicine \& Ethics (Fall): 500-508.

Wald, Priscilla. 2008. Contagious: Cultures, Carriers, and the Outbreak Narrative. Durham: Duke University Press.

Walt, Gill. 1988. Globalisation of International Health. The Lancet 351: 434-437.

WHO. 2009. Pandemic Influenza Preparedness and Response: A WHO Document. Geneva: Global Influenza Programme, World Health Organization.

\section{Other Sources}

Briand, Sylvie. 2009, 8 May. WHO Press Briefing 08/05/09. Available at: http:// www.who.int/mediacentre/multimedia/swineflupressbriefings/en/index. html.

Chan, Margaret. 2009, 29 April. WHO Press Briefing 29/04/09b. Available at: http://www.who.int/mediacentre/multimedia/swineflupressbriefings/en/ index.html.

Chan, Margaret. 2009, 8 May. World Is Better Prepared for Influenza Pandemic. Address to the ASEAN+3 Health Ministers' Special Meeting on Influenza (A)HlNl, Bangkok, Thailand. Available at: http://www.who.int/dg/ speeches/2009/asean_influenza_ahlnl_20090508/en/index.html.

Chan, Margaret. 2009a, 11 June. World Now at the Start of 2009 Influenza Pandemic Statement to the Press by WHO Director-General. Available at: http://www.who.int/mediacentre/news/statements/2009/hlnl_pandemic_phase6_20090611/en/index.html. 
Chan, Margaret. 2009b, 11 June. WHO Press Briefing 11/06/09. Available at: http://www.who.int/mediacentre/multimedia/swineflupressbriefings/en/ index.html.

Chan, Margaret. 2009, 17 June. WHO Welcomes Sanofi-Aventis's Donation of Vaccine. Statement by the WHO Director-General. Available at: http:// www.who.int/mediacentre/news/statements/2009/vaccine_donation_20090617/en/index.html.

Council of Europe Parliamentary Assembly. 2010, 24 June. Verbatim Report-Twenty-Sixth Sitting of the Parliamentary Assembly of the Council of Europe. Available at: http://assembly.coe.int/Main.asp?/Documents/ Records/2010/E/10062441500.htm.

Flynn, Paul. 2010, 7 June. The Handling of the H1N1 Pandemic: More Transparency Needed [Doc No. 12283-Passed by the Council of Europe 2010, 24 June]. Strasbourg: Social Health and Family Affairs Committee, Council of Europe.

Fineberg, Harvey. 2010, 14 April. WHO Press Briefing 19/05/10. Available at: http://www.who.int/mediacentre/multimedia/swineflupressbriefings/en/ index.html.

Fukuda, Keiji. 2009, I May. WHO Press Briefing 01/05/09. Available at: http:// www.who.int/mediacentre/multimedia/swineflupressbriefings/en/index. html.

Fukuda, Keiji. 2009, 5 May. WHO Press Briefing 05/05/09. Available at: http:// www.who.int/mediacentre/multimedia/swineflupressbriefings/en/index. html.

Fukuda, Keiji. 2009, 22 May. WHO Press Briefing 26/05/09. Available at: http://www.who.int/mediacentre/multimedia/swineflupressbriefings/en/ index.html.

Fukuda, Keiji. 2009, 26 May. WHO Press Briefing 26/05/09. Available at: http://www.who.int/mediacentre/multimedia/swineflupressbriefings/en/ index.html.

Fukuda, Keiji. 2009, 24 September. WHO Press Briefing 26/05/09. Available at: http://www.who.int/mediacentre/multimedia/swineflupressbriefings/en/ index.html.

Fukuda, Keiji. 2009, 3 December. WHO Press Briefing 03/12/09. Available at: http://www.who.int/mediacentre/multimedia/swineflupressbriefings/en/ index.html.

Wodarg, Wolfgang. 2009, 18 December. Faked Pandemics-A Threat to Health. Motion of a Recommendation by the Parliamentary Assembly of the Council of Europe Doc. 122110. Strasbourg: Council of Europe. 